\title{
1 Canonical Wnt Signaling is Involved in Anterior Regeneration of the
}

\section{Annelid Aeolosoma viride}

$7 \quad{ }^{1}$ Department of Life Science, National Taiwan University, Taipei 10617, Taiwan (R.O.C.)

$9{ }^{\dagger}$ These authors contributed equally to the manuscript

10

$11 *$ Correspondence should be addressed to J-H. C. (chenjh@ntu.edu.tw)

14 Keywords: canonical Wnt signaling, annelid regeneration, blastema proliferation and

15 differentiation

16

17 Funding: Undergraduate Student Joining Scientific Project of National Science Council, Taiwan 


\section{Abstract}

22 Annelids are regenerative animals, but the underlying mechanisms await to be discovered.

23 Because Wnt pathway is involved in animal regeneration to varying extents, we used

24 Aeolosoma viride to interrogate whether and how this pathway plays a role in annelid anterior

25 regeneration. We found that the expression of wnt4, 8 -catenin and nuclear-localized $\beta$-catenin

26 protein were up-regulated during blastemal formation and down-regulated as anterior

27 structures gradually reformed. Consistent with potential Wnt activities in the blastema,

28 treatments with either Wnt pathway activator (azakenpaullone) or inhibitor (XAV939) inhibited

29 head regeneration, which further supports a role of Wnt pathway during anterior regeneration.

30 Detailed tissue-level examines demonstrated that wound closure and blastemal cell

31 proliferation were impaired by over-activating the pathway, and that neuronal and musculature

32 differentiation were affected under Wnt inhibition. Combined, gene expression and chemical

33 inhibitor data suggest the presence of dynamic Wnt activities at different anterior regeneration

34 stages: an initial low activity may be required for wound closure, and the following activation

35 may signal blastemal formation and cell differentiation. In a nutshell, we propose that the

36 canonical Wnt signaling regulates blastemal cellular responses during annelid regeneration. 


\section{Introduction}

41 Among regeneration models, researches from hydra and planarian have uncovered many

42 cellular and molecular mechanisms (King \& Newmark, 2012; E. M. Tanaka \& Reddien, 2011). To

43 gain more perspectives into animal regeneration and to relate to broader evolutionary

44 implications, researches in other emerging models are indispensable. Annelids are known for

45 regeneration capabilities and some underlying mechanisms are evolutionarily shared with other

46 animals. For example, similar to the neoblasts of planarian (King \& Newmark, 2012; E. M.

47 Tanaka \& Reddien, 2011), Enchytraeus japonensis and Pristina leidyi maintain stem cells in every segment for regeneration (Myohara, 2012; Yoshida-Noro \& Tochinai, 2010; Zattara,

49 Turlington, \& Bely, 2016). Proliferative stem cells of planarian and Eisenia foetida express

50 pluripotent factors, such as oct4, nanog and sox2 (Onal et al., 2012; Zheng, Shao, Diao, Li, \&

51 Han, 2016). Consistent with the requirement of innervation for vertebrate limb regeneration

52 (Bryant, Endo, \& Gardiner, 2002), diverted neuron fiber induces ectopic axis in Eisenia annelids

53 (Bely, 2014). However, whether any molecular mechanism regulates annelid regeneration is not

54 clear yet (Bely, 2014).

56 Canonical Wnt signaling pathway (i.e. the Wnt/ $\beta$-catenin pathway) plays major roles in various

57 regenerative models. In hydra, injury induced apoptosis triggers the secretion of wnt3 from

58 dying cells and activates the oral pole regeneration (Chera et al., 2009). Knocking-down Wnt

59 pathway genes affect the anterior-posterior axial registration during planarian regeneration

60 (Augustin et al., 2006; Broun, Gee, Reinhardt, \& Bode, 2005; Gurley, Rink, \& Alvarado, 2008; 
61 Iglesias, Gomez-Skarmeta, Saló, \& Adell, 2008; King \& Newmark, 2012; Lengfeld et al., 2009;

62 Petersen \& Reddien, 2008; E. Tanaka \& Weidinger, 2008). Additionally, activating Wnt signaling enhances fin and limb regeneration in zebrafish and axolotl (Kawakami et al., 2006; Yokoyama,

64 Ogino, Stoick-Cooper, Grainger, \& Moon, 2007). In Xenopus laevis, activation of Wnt pathway

65 rejuvenates the regenerative ability of aged limbs (Yokoyama et al., 2007). Therefore, Wnt pathway is likely to regulate regeneration in other models.

Here, we used an emerging annelid regeneration model Aeolosoma viride to interrogate the involvement of canonical Wnt pathway in annelid regeneration (C.-P. Chen et al., 2020). A. viride belongs to Aeolosomaitidae, Annelida, and is phylogenetically classified as "clitellate-like

71 polychaetes" by morphological or molecular evidences (Hessling \& Purschke, 2000; Zrzavý, Říha,

72 Piálek, \& Janouškovec, 2009). A. viride is a freshwater annelid, typically ranges 2-3 mm in length and 0.1-0.2 $\mathrm{mm}$ in width with brown spots scatter on its semitransparent epithelium. In lab conditions, $A$. viride only reproduce asexually by adding posterior segments, and the progeny detaches from the parent worm via paratomic fission (Falconi, Gugnali, \& Zaccanti, 2015). Taking the advantage of its semitransparent appearance, we are able to directly observe its

77 internal organs, such as horseshoe-shaped mouth and the digestive tract (Fig. 1A). In our preliminary tests, we found $A$. viride can robustly regenerate anterior segments in 5 days (C.-P. 
83 In this report, we first showed transcriptional activation of wnt4 and 8 -catenin during

84 regeneration. Then, to assay Wnt pathway activity, we labeled nuclear localized $\beta$-catenin

85 protein by immunohistochemistry. We found blastemal formation was accompanied with

86 increasing levels of nuclear $\beta$-catenin between 12-24 HPA, which was followed by dropping

87 levels of nuclear $\beta$-catenin when anterior structures gradually reformed. To functionally

88 interrogate the pathway, we treated the worms with chemical inhibitors and found that both

89 activating and inhibiting the pathway impaired regeneration. Further short-term treatments

90 demonstrated that the chemical activator blocked wound closure and blastema formation;

91 while the inhibitor affected neuron and muscle regeneration in the blastema. Lastly, we labeled

92 proliferating cells and found that cell proliferation in wound tissue was inhibited when over-

93 activating Wnt pathway. The dynamic changes of nuclear $\beta$-catenin level and discrete cellular

94 responses under inhibitor treatments suggest that wound closure, blastemal formation and cell

95 differentiation depends on mild activation of endogenous Wnt pathway. Tilting the balanced

96 pathway activity to either extremity impaired complete tissue regeneration. 


\section{Results}

\section{Wnt pathway is activated in the regenerating blastema}

99 To investigate whether Wnt pathway is involved in regeneration, we first tested the

100 spatiotemporal expression patterns of wnt4, wnt8 and B-catenin by whole-mount in situ

101 hybridization (WMISH, Fig. 1). Upon amputation, the cutting plane was immediately covered by

102 wnt4 expressing epithelial cells (Fig. 1C). Then the epithelial wnt4 signal diminished from the

103 first hour-post-amputation (HPA) to 6 HPA before the gene was activated again at the wound

104 from 12 HPA (Fig. 1D-F). The wnt4 signal persisted in blastema until head structures completely

105 reformed at 120 HPA (Fig. 1K). On the contrary, we did not detect significant up-regulation of

106 wnt8 throughout the repairing process (Fig. 1M-U'), suggesting preferential Wnt ligand

107 activation during regeneration. 8-catenin was activated from 24 HPA through 72 HPA and

108 diminished when nascent head structures became recognizable at 96 HPA (Fig. 1DD).

110 Additionally, we observed wnt4 and 6 -catenin expression at the posterior $1 / 4^{\text {th }}$ segment of

111 intact worms (Fig. 1B and V) where asexual fission occurs and EdU labeled proliferating cells are

112 enriched (C.-P. Chen et al., 2020; Falconi et al., 2015) The expression of wnt4 and B-catenin at

113 this domain suggest that these genes may regulate the development of posterior growth zone,

114 like other multipotent genes, such as piwi, vasa and nanos in other annelids (Gazave et al., 2013;

115 Kozin \& Kostyuchenko, 2015; Zheng et al., 2016).

117 In most studied models, active Wnt signaling cascade stabilizes cytoplasmic pool of $\beta$-catenin

118 protein, which then translocate and accumulate in the nuclei and mediate downstream gene 
119 transcription (Clevers \& Nusse, 2012). We labeled $\beta$-catenin protein by immunohistochemistry

120 to evaluate the pathway activity during regeneration (Fig. 2). Combining with nuclear staining,

121 we found $\beta$-catenin localized in the nuclei of regenerating blastema (Fig. 2A-D). Because

122 nascent blastema was hardly distinguishable during early wound closure, we quantified the

123 ratio of $\beta$-catenin-enriched $\left(\beta\right.$-catenin $\left.{ }^{+}\right)$nuclei to the blastemal nuclei from 12 HPA (Fig. $2 R$ ). We

124 found that when the proliferating blastema gradually became distinguishable from wound

125 epithelium between 12 to $24 \mathrm{HPA}$, the ratio of $\beta$-catenin ${ }^{+}$nuclei increased. Then the ratio of $\beta$ -

126 catenin $^{+}$nuclei decreased as head regeneration completed. Combined with ISH data, we

127 proposed that Wnt signaling is activated in the proliferating blastema from 12 HPA and is

128 gradually silenced until regeneration completes at 120 HPA.

\section{Perturbing Wnt pathway inhibited $A$. viride regeneration}

131 We next asked whether tuning Wnt pathway can modulate $A$. viride regeneration or not. To

132 further test the role of Wnt signaling in $A$. viride regeneration, we incubated amputated worms

133 in chemical activators: Wnt Agonist, Alsterpaullone (a GSK-3 $\beta$ inhibitor) and 1-azakenpaullone

134 (Azkp, a GSK-3ß inhibitor) or inhibitor: XAV939 (XAV, a tankyrase inhibitor and, in turn stabilizes

135 axin Broun et al., 2005; Huang et al., 2009; Kunick, Lauenroth, Leost, Meijer, \& Lemcke, 2004).

136 Since endogenous Wnt pathway was activated during blastemal initiation, we expected

137 chemically activating Wnt pathway may enhance blastemal proliferation. However, to our

138 surprise, these compounds inhibited A. viride regeneration in dose-dependent manners (Fig.

$1393 \mathrm{~A}-\mathrm{D})$. For consistency, we applied $0.25 \mu \mathrm{M}$ Azkp or $5 \mu \mathrm{M}$ XAV in the following experiments. We

140 found smaller blastema of Azkp treated worms, suggesting over-activating Wnt pathway may 
141 inhibit blastema formation (Fig. 3H-J). On the other hand, XAV did not affect blastema

142 formation (Fig. 3K-M), but worms did not regenerate prostomium (Fig. 3G, M).

143 Additionally, we validated the inhibitor effects by assaying the nuclear $\beta$-catenin level in Azkp or

144 XAV treated blastema (Fig. 2I-R). As expected, Azkp resulted in more nuclear localized $\beta$-catenin,

145 whereas XAV treated blastema showed less nuclear $\beta$-catenin than control at 24 and 48 HPA,

146 demonstrating the efficacy of these inhibitors.

148 In the above assays, we applied treatments throughout regeneration and found both Wnt

149 pathway activator and inhibitor impaired regeneration. From nuclear $\beta$-catenin level of control

150 worms, we found dynamic Wnt activities during regeneration. We hypothesized that different

151 Wnt pathway activities may be required at different regeneration stages. To test the hypothesis,

152 we applied $24 \mathrm{H}$ pulse of Azkp or XAV for detailed temporal examinations (Fig. 3N-O). We found

153 treatments of Azkp and XAV before 72 HPA resulted in greater incidences of defective

154 regeneration, suggesting the activity of Wnt pathway is required during early regeneration

155 stages. However, the two treatments showed different effective time windows: 0-24 HPA

156 amputees were sensitive to Azkp, while 24-48 HPA amputees were sensitive to XAV. Combining

157 nuclear $\beta$-catenin data with $24 \mathrm{H}$ pulse treatments, we propose that wound tissue may require

158 low Wnt pathway activities during initial 0-24 HPA and then high activities between 24-48 HPA.

160 Perturbing Wnt pathway impaired neuron and muscle regeneration

161 Our key criteria for assaying anterior regeneration of $A$. viride are the reformation of head

162 structures (the prostomium, the horseshoe-shaped mouth in the peristomium, Fig. 1) and free 
163 gliding behavior on substrates. Since the majority of Azkp and XAV treated amputees failed to

164 meet these criteria, we asked whether the neuron or muscle regeneration is impaired. We first

165 examined the underlying innervation by immunolabeling acetylated $\alpha$-tubulin (Fig. 4). After five

166 days of regeneration, control $A$. viride recovered anterior neuron connections between the

167 neuropils and the ventral nerve cords through the circumesophageal commissures, as well as

168 dorsal-anterior sensory organs of the prostomium (Fig. 4A, D; Hessling \& Purschke, 2000). Azkp

169 treated worms failed to regenerate prostomium, and the ventral nerve cords of the remaining

170 tissue showed degeneration and did not extend anteriorly to form circumesophageal

171 commissures or neuropils (Fig. 4E, H). The XAV treated worms showed partial recovery of the

172 neuron connection from the ventral nerve cords to the neuropil through the circumesophageal

173 commissures (Fig. 4I, L). However, the prostomium and the innervation from neuropil to the

174 dorsal-anterior sensory organs were missing, which may be the main reason for the failure of

175 behavioral recovery.

177 The rhomboid shape-arrayed muscle net underlying the intact prostomium supports its flat

178 shape and multi-directional movements (Fig. 4B). Such specialized musculature of prostomium

179 can be distinguished from the rest of body segments, which is composed by the perpendicular-

180 arrayed longitudinal and circular muscles. In addition to the observed neuronal regeneration

181 defects, both Azkp- and XAV-treated worms did not regenerate the characteristic prostomium

182 musculature (Fig. 4F, J), which further supported the observed regeneration defects from

183 morphology and behavior. 
185 Over-activating Wnt signaling by Azkp resulted in blastemal cell proliferation defects

186 From our previous report, we observed that wound blastema increased in size and showed the

187 most cell proliferation between 24 and 48 HPA (Fig. 3E-G; C.-P. Chen et al., 2020). At the same

188 stages, Azkp treated wound blastema did not show comparable size change like control or XAV

189 treated worms (Fig. 3E-M). Despite Azkp and XAV treatments both inhibited anterior

190 regeneration, subtle differential cellular responses to Wnt activity perturbation may exist.

191 Because the blastema of Azkp treated wounds were smaller, we hypothesized that cell

192 proliferation can be impaired in these worms. We first examined cumulative cell proliferation

193 by 5-ethynyl-2'-deoxyuridine (EdU) pulse between 24 and 48 HPA (Fig. 5B, G, L). EdU' cells at

194 the blastema were less condensed in Azkp treated worms than in control and XAV, suggesting

195 that over-activating Wnt compromised blastemal cell proliferation and resulted in smaller

196 blastema. Additionally, we observed that the $\mathrm{EdU}^{+}$cells were ectopically enriched in the $2^{\text {nd }}$

197 segment of Azkp treated worms (Fig. 5G). From single z section images, we found the secondary

$198 \mathrm{EdU}^{+}$cell domain located at the anterior tip of the midgut (Fig. 5J), which was observed to

199 lesser extents in control and XAV treated worms (Fig. 5E, O-P).

201 Additionally, we also labeled proliferating cells at 48 HPA by anti-phospho-histone 3 antibody



203 was significantly lower in the Azkp treated blastema than control and XAV treatments (Control:

$20455 \pm 33.4 ;$ Azkp: 18.8 $\pm 8.2 ;$ XAV: 59.2 $\pm 30.7 ; p$ of Control-Azkp $=0.01 ; p$ of Control-XAV $=0.89 ; p$ of

205 Azkp-XAV = 0.001; Mann-Whitney U-test). Combining EdU and H3P assays, Azkp-induced 
bioRxiv preprint doi: https://doi.org/10.1101/2020 03.01.972448; this version posted March 2, 2020. The copyright holder for this preprint (which was not certified by peer review) is the author/funder, who has granted bioRxiv a license to display the preprint in perpetuity. It is made available under aCC-BY-NC-ND 4.0 International license.

206 blastemal formation defects can be attributed to lacking proliferation at blastema and mis-

207 regulation of proliferating domain at the $2^{\text {nd }}$ segment.

208 


\section{Discussion}

210 In this report, we interrogated the involvement of Wnt pathway in A. viride anterior

211 regeneration. Wnt pathway activities were dynamic during regeneration, with the highest

212 activity at 24 HPA when the wound blastema was actively proliferating. Long term incubation

213 with either chemical inhibitor or activator of Wnt pathway impaired regeneration. Further

214 temporal experiments suggested the requirements for the relatively low Wnt activity between

215 0-24 HPA and high activity between 24-48 HPA. Examinations of innervation, musculature and

216 cell proliferation revealed the underlying cellular responses under treatments. By integrating

217 current observations, we provide the following reasonings about how Wnt pathway is involved

218 in $A$. viride regeneration.

\section{A. viride regeneration depends on dynamic Wnt signaling activities}

221 The dynamic nuclear $\beta$-catenin levels suggest Wnt pathway activity varies through stages of $A$.

222 viride regeneration. Thus, long-term treatments by either Azkp or XAV may counteract against

223 endogenous Wnt activities at different stages and result in the ultimate regeneration failure.

224 Then, we further narrowed the treatment into $24 \mathrm{H}$ pulses. We found that the two chemical

225 inhibitors were effective before 72 HPA when normal wound tissue repaired through wound

226 closure, blastemal formation and partial differentiation stages. Immediately after amputation,

227 we observed that the wound was covered by nearby wnt4 expressing epithelium, and then

228 wnt4 expression was down-regulated from 1 HPA until being activated again at the blastema

229 from 12 HPA. Downregulation of wnt4 at the wound site suggests that the wnt4-mediated Wnt

230 signaling was silenced during wound healing. Therefore, Azkp treatment at this stage may 
231 counteract the Wnt inactivation as well as compromise the following blastemal cell

232 proliferations. Alternatively, over-activating Wnt pathway may override endogenous activation

233 between 12-24 HPA and turn the tissue into non-permissive conditions for regeneration. Then,

234 XAV inhibited regeneration during 24-48 HPA when the most $\beta$-catenin accumulated in the

235 nuclei. Although blastemal proliferation was not affected by XAV, the underlying innervation

236 and prostomium musculature could not completely recover. Because the appearance of neuron

237 and muscle cells are signatures of blastemal cell differentiation from nascent stem cells, we

238 propose that the endogenous Wnt activation at 24 HPA can be required for blastemal cell

239 differentiation.

241 Collectively, as summarized in Fig. 6, our data suggest that the progression of regeneration is

242 dependent on different Wnt activities: wound closure and initial repairing occur under low Wnt

243 activity (0-24 HPA); high Wnt activity initiates blastemal proliferation (24 HPA); blastemal

244 differentiation requires median Wnt activity (24-48 HPA); continued completion of

245 regeneration after 72 HPA is inert to exogenous Wnt activity modulators.

247 Wnt signaling may not regulate anterior-posterior identity of regenerating $\boldsymbol{A}$. viride

248 Wnt pathway is indispensable for defining axis during embryogenesis and regeneration of many

249 animal models (Broun et al., 2005; Chera et al., 2009; Gurley et al., 2008; Iglesias et al., 2008;

250 Leclère, Bause, Sinigaglia, Steger, \& Rentzsch, 2016; Lengfeld et al., 2009; Petersen \& Reddien,

251 2008; E. Tanaka \& Weidinger, 2008). In planarian, activating Wnt pathway promotes posterior

252 regeneration at the anterior wound; while inhibiting the pathway induces head formation at 
253 the posterior wound (Iglesias et al., 2008; Petersen \& Reddien, 2008). If axial patterning of Wnt

254 pathway is evolutionarily conserved in A. viride, we anticipated that anterior regeneration

255 would be enhanced when we inhibited the pathway, and that posterior regeneration would be

256 enhanced when we over-activated the pathway. However, our current data and methods do

257 not support such hypothesis, i.e. XAV did not enhance anterior regeneration. Additionally, we

258 did not observe ectopic head regeneration from the posterior wounds from our preliminary

259 XAV treatments. Prostomium and anterior neuronal regeneration were inhibited by XAV

260 treatments, suggesting other side effects existed. On the other hand, anterior regeneration was

261 inhibited when the pathway was over-activated by Azkp, but we could not confidently claim

262 that these Azkp treated wounds were transformed to posterior identity for lacking axial

263 markers. Therefore, labeling anterior-posterior molecular markers will be the future direction

264 for testing whether Wnt pathway regulates the axial identity of regenerating $A$. viride.

266 GSK-3 $\beta$ activity is required for $\boldsymbol{A}$. viride neuronal regeneration and maintenance

267 Innervation to the regenerating tissues can be necessary and sufficient for complete

268 regeneration in many systems (A. Kumar \& Brockes, 2012). For example, bisected salamander

269 limbs cannot regenerate if the remaining neuron is removed (A. Kumar \& Brockes, 2012);

270 ectopic neuron growth initiates ectopic blastemal formation in annelids (Bely, 2014). In

271 planarian, $\beta$-catenin-1 localizes in the nuclei of brain and ventral nerve cords and is required for

272 brain patterning during regeneration (Hill \& Petersen, 2015; Sureda-Gómez, Martín-Durán, \&

273 Adell, 2016). Azkp treatment results in neuronal regeneration defects in planarian, such as

274 smaller cephalic ganglia and ectopically projected visual axons (Adell, Marsal, \& Saló, 2008). 
275 Consistent with this idea, the Azkp treated A. viride did not regenerate neurons and showed

276 degenerating ventral nerve cords, suggesting the requirement of GSK-3 $\beta$ in neuronal

277 regeneration and maintenance. On top of that, planarian neuron regeneration is required for

278 blastemal morphogenesis (Adell et al., 2008). In A. viride, the blastemal cell proliferation and

279 innervation were both impaired when GSK-3 $\beta$ was inhibited by Azkp, suggesting a linkage

280 between neuron regeneration and blastema formation. If neuron is generally required for

281 regeneration in diverse animal models, then it is likely that $A$. viride blastema formation can be

282 also regulated by innervation, which possibly requires active GSK-3ß. However, the epistatic or

283 mutual regulation of innervation and blastema formation in $A$. viride is not clear yet and

284 warrants further investigations.

285

286 In summary, we demonstrated that proper regulation of Wnt signaling activities is required for

287 different stages of $A$. viride anterior regeneration. As an echo to other regeneration models, our

288 data further generalize the involvement of Wnt signaling to regeneration in an evolutionarily

289 conserved perspective. In the future, more sophisticate approaches, such as CRISPR/Cas9

290 mutagenesis, will provide detailed molecular mechanisms of annelid regeneration as well as

291 comparative regeneration biology in a broader context. 


\section{Materials and methods}

\section{Animal husbandry}

295 Animal husbandry followed Chen et al. 2020. The whole culturing colony was asexually

296 descended from one single worm to avoid genetic differences.

\section{Amputation}

299 Before anterior amputation, $A$. viride was first bisected between the midgut and hindgut

300 junction (Fig. 1A). By this method, we aimed to synchronize the posterior segments and to

301 prevent any proliferating progeny interfering with assessing successful regeneration (C.-F. Chen,

302 Sung, Chen, \& Chen, 2018). During synchronization, $A$. viride was cultured in $\mathrm{ASW}$ at $25^{\circ} \mathrm{C}$

303 without feeding. The pygidium recovered in three days. Then, the anterior segments were

304 amputated between the foregut and midgut junction (Fig. 1A).

By 144 hour-post-amputation (HPA), successful anterior regeneration was assessed by the

307 following criteria: 1) muscle contraction in prostomium and peristomium, 2) appearance of

308 horseshoe-shaped mouth (Fig. 1A); 3) voluntary gliding behavior on substrates. Regeneration

309 rates were assayed by averaging the proportion of successful regeneration worms form at least

3103 biological replicates. Each replicate was started from $>10$ worms at 0 HPA.

\section{Isolation of $A$. viride wnt4, wnt8, and B-catenin sequences}

313 Total RNA of $A$. viride was purified from intact worms by TRIzol (Thermo Fisher Scientific;

314 Waltham, MA) following manufacturer's instructions. Then, the cDNA library was reverse- 
315 transcribed by SuperScriptIII Reverse Transcriptase (Thermo Fisher Scientific) with oligo dT as

316 the first strand primer. Using cDNA library as template and degenerated primers (Table 1), we

317 amplified target fragments by PCR, cloned the fragments into T\& $\mathrm{A}^{\mathrm{TM}}$ vector (Yeastern Biotech

318 Co., Taiwan), and sequenced the insert fragment.

320 For 3' Rapid Amplification of cDNA Ends (3' RACE), the cDNA library was primed by 3' end

321 anchor primer (3' AP, Table 2). Then gene specific internal primers and 3' AP head primer were

322 used for nested PCR (Table S2). The amplified products were cloned into T\&A $\mathrm{A}^{\mathrm{TM}}$ vector and

323 sequenced.

325 To amplify the 5' end sequence, we performed 5' RACE by reverse transcribing the first strand

326 cDNA by gene specific primer (Table 2). Then multiple deoxycytidines were added to the $3^{\prime}$ end

327 of cDNA by terminal deoxynucleotidyl transferase (ThermoFisher). The gene specific primers

328 and universal $5^{\prime}$ end anchor primer (5' AP, Table 2) were used to amplify the $5^{\prime}$ end sequence.

329 Secondary nested PCR with 5' AP head primer (Table 2) was used to further amplify the specific

330 sequence, which is followed by cloning and sequencing as described above.

\section{Gene homology analysis}

333 Thirteen subfamilies of Wnt homologues proteins were previously identified in

334 Lophotrochozoan genomes (Cho, Vallès, Giani, Seaver, \& Weisblat, 2010; Prud'homme, Lartillot,

335 Balavoine, Adoutte, \& Vervoort, 2002). To test the homology of $A$. viride wnt genes, we first

336 used SMART protein analysis (http://smart.embl.de/) to identify the WNT domain of 
337 Lophotrochozaon Wnt genes and aligned them by the default parameter of MUSCLE of MEGA7

338 program (S. Kumar, Stecher, \& Tamura, 2016). Then, the phylogenetic relationship of wnts were

339 resolved by Neighbor-joining method by p-distance model with 10,000 bootstrap repeats

340 clustering $A$. viride wnt4 and wnt8 within the corresponding subfamilies (Fig. 7).

342 The cloned $\beta$-catenin protein encodes 12 characteristic armadillo domains (ARM) by SMART

343 analysis. The amino acid sequence of $\beta$-catenin showed higher similarity to $\beta$-catenin than $\alpha$ -

344 catenin or $\gamma$-catenin homologs by NCBI protein BLAST, confirming the sequence identity as Av-

345 B-catenin.

347 Chemical inhibitor treatments

348 Anterior amputated $A$. viride were washed with treatment solutions four times before

349 incubating either through whole regeneration process (Fig. $3 \mathrm{~A}-\mathrm{D}$ ) or at $24 \mathrm{H}$ intervals (Fig. 3N-O).

350 1-Azakenpaulone (Azkp; MilliporeSigma, Burlington, MA), XAV939 (XAV, MilliporeSigma),

351 Alsterpaullone (MilliporeSigma), Wnt Agonist (MilliporeSigma) were dissolved in dimethyl

352 sulfoxide (DMSO) as stock solutions, and then diluted in artificial spring water (ASW) as working

353 solutions at designed concentrations. Control solution was prepared with comparable

354 concentrations of DMSO in ASW.

356 Whole-mount Immunofluorescence (WMIF)

357 Worms were anesthetized by menthol saturated ASW, and then fixed with 4\% PFA-ASW

358 overnight at $4^{\circ} \mathrm{C}$. Then the samples were washed 5 times with phosphate buffered saline (PBS, 
$\mathrm{pH}=7.4$ ) containing $0.1 \%$ Triton $\mathrm{X}-100$ (PBST). After washing, the fixed worms were rinsed with

$100 \%$ methanol 3 times at RT and stored at $-20^{\circ} \mathrm{C}$ until proceeded to immunohistochemistry.

362 To begin immunohistochemistry, the samples were re-hydrated through series of $66 \%$ and $33 \%$

363 methanol in PBST washes and additional washes in PBST for 5 times. Then, the samples were

364 treated with $5 \mu \mathrm{g} / \mathrm{mL}$ protease $\mathrm{K}$ solution at RT for 5 minutes, followed by incubation in 2

$365 \mathrm{mg} / \mathrm{mL}$ glycine for 5 minutes and post-fixation with 4\% PFA-PBST at RT for 1 hour. After post-

366 fixation, the samples were washed 3 times with PBST, and immersed in the blocking solution

367 (PBST with 3\% bovine serum albumin and 5\% Goat serum) for up to 1 hour at RT. Primary

368 antibody incubation: Rabbit-anti- $\beta$-catenin antibody (in 1:800 dilution; MilliporeSigma, C2206),

369 Rabbit-anti-H3P antibody (in 1:1000 dilution; MilliporeSigma, 06-570) or Mouse-anti-acetylated

$370 \quad \alpha$-tubulin (in 1:1000 dilution; MilliporeSigma, T7451) was applied overnight at $4^{\circ} \mathrm{C}$ with blocking

371 solution as diluent. After 6 times washing with PBST, samples were incubated in fluorophore

372 conjugated Goat anti-Rabbit antibody or Goat anti-Mouse antibody (in 1:400 dilution; Thermo

373 Fisher Scientific) for 2 hours at RT with blocking solution as diluent. F-Actin staining was

374 performed on no methanol treated samples as follows: After 1 hour blocking by 1\% BSA-PBST at

375 RT, we incubated samples in BODIPY ${ }^{\circledR}$ FL Phallacidin (1:40 dilution in blocking buffer, Thermo

376 Fisher Scientific) at RT for 1 hour. The nuclei were counter-stained with $1 \mu \mathrm{g} / \mathrm{mL}$ DAPI-PBST for

37720 minutes at RT. After 4 times washes by PBST, the samples were immersed and cleared in

$378 \quad 80 \%$ glycerol-PBS with $0.1 \% \mathrm{NaN}_{3}$ before mounting on slides. 
381 DNA templates of riboprobes were amplified by gene specific primers (Table 3) and cloned into

$382 T \& A^{T M}$ vector. After confirming the desired orientations by sequencing, we linearized the

383 plasmids as templates for DIG-labeled riboprobes synthesis by T7 polymerase (Thermo Fisher

384 Scientific) with DIG RNA labeling mix (MilliporeSigma).

386 The WMISH protocol was adopted from zebrafish WMISH protocol (Thisse \& Thisse, 2008).

387 Sample preparation was similar to WMIF, but PBS with 0.1\% Tween-20 (PBSTw) was used

388 instead of PBST. Pre-hybridization was performed in $\mathrm{HYB}^{-}$buffer (50\% formamide, 5X SSC, and

$3890.1 \%$ Tween-20 in DEPC-treated $\mathrm{H}_{2} \mathrm{O}$ ) at $65^{\circ} \mathrm{C}$ for 1 hour. The riboprobes were diluted at 1

$390 \mathrm{ng} / \mu \mathrm{L}$ in $\mathrm{HYB}^{+}$buffer (HYB- buffer with $50 \mu \mathrm{g} / \mathrm{mL}$ Heparin and $0.5 \mathrm{mg} / \mu \mathrm{L}$ yeast tRNA;

391 MilliporeSigma). Hybridization was performed at $65^{\circ} \mathrm{C}$ overnight. Then samples were washed at

$39265^{\circ} \mathrm{C}$ by serial dilutions of $\mathrm{HYB}^{-}$and 2 X SSCTw (2X SSC with $0.1 \%$ Tween-20) from 2:1 to 1:2 ratio,

393 one 2 X SSCTw wash, two 0.2 XSCTw (0.2X SSC with $0.1 \%$ Tween-20) washes, and another serial

394 dilution of 0.2 XSSCTw and PBSTw from 2:1 to 1:2 ratio. The samples were washed once by

395 PBSTw at RT and immersed in blocking solution (5\% BSA in PBSTw) at $4{ }^{\circ} \mathrm{C}$ overnight. The

396 samples were then incubated in 1:10,000 diluted anti-DIG-AP antibody (MilliporeSigma) in

397 blocking buffer at $4{ }^{\circ} \mathrm{C}$ overnight. Then samples were washed 10 times with PBSTw and 3 times

398 with AP buffer (0.1 M Tris-Cl, $0.05 \mathrm{M} \mathrm{MgCl}_{2}, 0.1 \mathrm{M} \mathrm{NaCl}$ and $0.1 \%$ Tween-20 in DEPC-treated

$399 \mathrm{H}_{2} \mathrm{O}$ ). NBT and BCIP were added in AP buffer for colorimetric reaction at $4{ }^{\circ} \mathrm{C}$ overnight. Finally,

400 the reaction was stopped by 5 times PBSTw washes and once $100 \%$ methanol wash before

401 immersing in $80 \%$ glycerol-PBS for mounting.

402 


\section{EdU labeling}

404 Regenerating $A$. viride were incubated in $100 \mu \mathrm{M}$ 5-ethynyl-2'-deoxyuridine (EdU; Thermo

405 Fisher Scientific) diluted in ASW from 24 to 48 HPA, when blastemal cells showed the most

406 proliferation (C.-P. Chen et al., 2020). Then, worms were anesthetized and fixed as WMIF

407 method. After protease $\mathrm{K}$ treatment and re-fixation, Click-iT ${ }^{\circledR}$ reaction was performed as

408 manufacturer's instruction (Click-i $\mathrm{T}^{\circledR}$ EdU Imaging Kits, Thermo Fisher Scientific). Experiments

409 validated the specificity of EdU is shown in Fig. 8.

\section{Microscopy}

412 Images of regenerating worms and in situ hybridization were taken by Stereo Investigator (MBF

413 Bioscience), Zeiss Axio Observer Z1 or Zeiss Axio Imager A1 microscope with a Zeiss AxioCam

414 MRc CCD camera. Fluorescent specimens were imaged by Leica TCS SP5 confocal laser scanning

415 microscope. Contrasts of images were adjusted as the corresponding control images by ImageJ.

416 Figures were prepared by Illustrator CC (Adobe).

\section{Image quantification}



420 by Fiji: in brief, the images were pre-processed by "Subtract Background", "Median" and the

421 nuclei were quantified by "3D Maxima Finder" (Boudier et al., 2013). EdU nuclei quantification

422 was performed according to Cai et. al, 2009 with minor modifications (Cai, Vallis, \& Reilly, 2009):

423 analysis of particles was set $>12 \mu \mathrm{m}^{2}$ corresponding to the cell size and covered the entire $z$ 424 stack range of images. 


\section{Statistic analysis}

427 Difference of successful regeneration rates were tested by Cochran Q test and McNemar

428 change test. The ratio of $\beta$-catenin ${ }^{+}$nuclei was analyzed by two-tailed $t$-test, assuming equal

429 variances. Parametric unpaired $t$-test between treatments was performed for comparing the

430 ratio of $\mathrm{EdU}^{+}$nuclei in blastema to $2^{\text {nd }}$ segment with log-transformation. The number of $\mathrm{H}_{3} \mathrm{P}^{+}$

431 nuclei in the blastema was assayed by Mann-Whitney U-test. $p$ values less than 0.05 were

432 considered statistically significant.

\section{Declarations}

\section{Ethics approval and consent to participate}

436 All experimental treatments on $A$. viride were approved by the Environmental Protection and

437 Occupational Safety and Health Center, National Taiwan University.

\section{Availability of data and material}

440 All data generated or analyzed during this study are included in this published article, or

441 available upon reasonable request from the corresponding author.

\section{Competing interests}

444 The authors declare that they have no competing interests

\section{Authors' contributions}


bioRxiv preprint doi: https://doi.org/10.1101/2020.03.01.972448; this version posted March 2, 2020. The copyright holder for this preprint (which was not certified by peer review) is the author/funder, who has granted bioRxiv a license to display the preprint in perpetuity. It is made available under aCC-BY-NC-ND 4.0 International license.

447 CYC, WTY and JHC prepared the manuscript. CYC and WTY design and perform the experiments

448 and analyzed the data. All authors read and approved the final manuscript.

\section{Acknowledgements}

451 We would like to thank Dr. Eric Hill from Stowers Institute for Medical Research, Kansas City,

452 MO for suggestions and critics on the manuscript. We appreciate Dr. Jr-Kai Yu from Institute of

453 Cellular and Organismic Biology, Academia Sinica, Taiwan, for kindly providing access to the

454 confocal microscopy.

455 


\section{References}

Adell, T., Marsal, M., \& Saló, E. (2008). Planarian GSK3s are involved in neural regeneration. Development Genes and Evolution, 218(1-2), 89-103. https://doi.org/10.1007/s00427007-0199-3

Augustin, R., Franke, A., Khalturin, K., Kiko, R., Siebert, S., Hemmrich, G., \& Bosch, T. C. G. (2006). Dickkopf related genes are components of the positional value gradient in Hydra. Developmental Biology, 296(1), 62-70. https://doi.org/10.1016/j.ydbio.2006.04.003

Bely, A. E. (2014). Early events in annelid regeneration: a cellular perspective. Integrative and Comparative Biology, 54(4), 688-699. https://doi.org/10.1093/icb/icu109

Boudier, T., Ollion, J., Cochennec, J., Escude, C., Curie, M., Umr, C., ... Paris, C. (2013). TANGO : a generic tool for high-throughput 3D image analysis for studying nuclear organization. Bioinformatics, 29(14), 1840-1841. https://doi.org/10.1093/bioinformatics/btt276

Broun, M., Gee, L., Reinhardt, B., \& Bode, H. R. (2005). Formation of the head organizer in hydra involves the canonical Wnt pathway. Development, 132(12), 2907-2916. https://doi.org/10.1242/dev.01848

Bryant, S. V, Endo, T., \& Gardiner, D. M. (2002). Vertebrate limb regeneration and the origin of limb stem cells. The International Journal of Developmental Biology, 46(7), 887-896.

Cai, Z., Vallis, K. A., \& Reilly, R. M. (2009). Computational analysis of the number, area and density of gamma-H2AX foci in breast cancer cells exposed to (111)In-DTPA-hEGF or gamma-rays using Image-J software. International Journal of Radiation Biology, 85(3), 262271. https://doi.org/10.1080/09553000902748757 
478 Chen, C.-F., Sung, T.-L., Chen, L.-Y., \& Chen, J.-H. (2018). Telomere maintenance during anterior regeneration and aging in the freshwater annelid Aeolosoma viride. Scientific Reports, 8(1),

Chen, C.-P., Fok, S. K.-W., Hsieh, Y.-W., Chen, C.-Y., Hsu, F.-M., Chang, Y.-H., \& Chen, J.-H. (2020). General characterization of regeneration in Aeolosoma viride (Annelida, Aeolosomatidae). Invertebrate Biology, e12277. https://doi.org/10.1111/ivb.12277

Chera, S., Ghila, L., Dobretz, K., Wenger, Y., Bauer, C., Buzgariu, W., ... Galliot, B. (2009). regeneration. Developmental Cell, 17(2), 279-289.

Cho, S.-J. J., Vallès, Y., Giani, V. C., Seaver, E. C., \& Weisblat, D. A. (2010). Evolutionary Dynamics of the wnt Gene Family: A Lophotrochozoan Perspective. Molecular Biology and Evolution, 27(7), 1645-1658. https://doi.org/10.1093/molbev/msq052

Falconi, R., Gugnali, A., \& Zaccanti, F. (2015). Quantitative observations on asexual reproduction of Aeolosoma viride (Annelida, Aphanoneura). Invertebrate Biology, 134(2), 151-161. https://doi.org/10.1111/ivb.12087 related to primordial germ cells. Developmental Biology, 382(1), 246-267. 
499 Gurley, K., Rink, J., \& Alvarado, A. (2008). Beta-catenin defines head versus tail identity during planarian regeneration and homeostasis. Science, 319(5861), 323-327. https://doi.org/10.1126/science.1150029

502

503

Hessling, R., \& Purschke, G. (2000). Immunohistochemical (cLSM) and ultrastructural analysis of the central nervous system and sense organs in Aeolosoma hemprichi (Annelida, Aeolosomatidae). Zoomorphology, 120(2), 65-78. https://doi.org/10.1007/s004350000022

Hill, E. M., \& Petersen, C. P. (2015). Wnt/Notum spatial feedback inhibition controls neoblast differentiation to regulate reversible growth of the planarian brain. Development, 142(24), 4217-4229. https://doi.org/10.1242/dev.123612

Huang, S.-M. A., Mishina, Y. M., Liu, S., Cheung, A., Stegmeier, F., Michaud, G. A., ... Cong, F. (2009). Tankyrase inhibition stabilizes axin and antagonizes Wnt signalling. Nature, 461(7264), 614. https://doi.org/10.1038/nature08356

Iglesias, M., Gomez-Skarmeta, J. L., Saló, E., \& Adell, T. (2008). Silencing of Smed-betacatenin1 generates radial-like hypercephalized planarians. Development, 135(7), 1215-1221. https://doi.org/10.1242/dev.020289

Kawakami, Y., Esteban, C. R., Raya, M., Kawakami, H., Martí, M., Dubova, I., \& Belmonte, J. C. I. (2006). Wnt/beta-catenin signaling regulates vertebrate limb regeneration. Genes Dev, 20(23), 3232-3237. https://doi.org/10.1101/gad.1475106

King, R., \& Newmark, P. (2012). The cell biology of regeneration. Journal of Cell Biology, 196(5), 553-562. https://doi.org/10.1083/jcb.201105099 
519 Kozin, V. V, \& Kostyuchenko, R. P. (2015). Vasa, PL10, and Piwi gene expression during caudal regeneration of the polychaete annelid Alitta virens. Development Genes and Evolution,

522 Kumar, A., \& Brockes, J. P. (2012). Nerve dependence in tissue, organ, and appendage regeneration. Trends in Neurosciences, 35(11), 691-699. https://doi.org/10.1016/j.tins.2012.08.003

Kumar, S., Stecher, G., \& Tamura, K. (2016). MEGA7: Molecular Evolutionary Genetics Analysis Version 7.0 for Bigger Datasets., 33(7), 1870-1874.

Kunick, C., Lauenroth, K., Leost, M., Meijer, L., \& Lemcke, T. (2004). 1-Azakenpaullone is a selective inhibitor of glycogen synthase kinase-3. Bioorganic \& Medicinal Chemistry Letters,

531 Leclère, L., Bause, M., Sinigaglia, C., Steger, J., \& Rentzsch, F. (2016). Development of the aboral domain in Nematostella requires $\beta$-catenin and the opposing activities of Six3/6 and

534 Lengfeld, T., Watanabe, H., Simakov, O., Lindgens, D., Gee, L., Law, L., ... Holstein, T. W. (2009). Multiple Wnts are involved in Hydra organizer formation and regeneration. Developmental

537 Myohara, M. (2012). What role do annelid neoblasts play? A comparison of the regeneration 538 patterns in a neoblast-bearing and a neoblast-lacking enchytraeid oligochaete. PLoS One, 7(5), e37319. https://doi.org/10.1371/journal.pone.0037319 
540 Onal, P., Grün, D., Adamidi, C., Rybak, A., Solana, J., Mastrobuoni, G., ... Rajewsky, N. (2012).

541 Gene expression of pluripotency determinants is conserved between mammalian and

542 planarian stem cells., 31(12), 2755-2769. https://doi.org/10.1038/emboj.2012.110

543 Petersen, C. P., \& Reddien, P. W. (2008). Smed- $\beta$-catenin-1 is required for anteroposterior

544 blastema polarity in planarian regeneration. Science, 319(5861), 327-330. https://doi.org/10.1126/science.1149943

546 Prud'homme, B., Lartillot, N., Balavoine, G., Adoutte, A., \& Vervoort, M. (2002). Phylogenetic analysis of the Wnt gene family: insights from lophotrochozoan members, 12(16), 1395-

Sureda-Gómez, M., Martín-Durán, J. M., \& Adell, T. (2016). Localization of planarian $\beta$-CATENIN-

$$
1 \text { reveals multiple roles during anterior-posterior regeneration and organogenesis. }
$$

552 Tanaka, E. M., \& Reddien, P. W. (2011). The cellular basis for animal regeneration.

$$
\text { Devlopmental Cell, 21(1), 172-185. https://doi.org/10.1016/j.devcel.2011.06.016 }
$$

554 Tanaka, E., \& Weidinger, G. (2008). Heads or tails: can Wnt tell which one is up? Nature Cell

556 Thisse, C., \& Thisse, B. (2008). High-resolution in situ hybridization to whole-mount zebrafish embryos. Nature Protocols, 3(1), 59-69. https://doi.org/10.1038/nprot.2007.514

558 Yokoyama, H., Ogino, H., Stoick-Cooper, C. L., Grainger, R. M., \& Moon, R. T. (2007). Wnt/beta559 catenin signaling has an essential role in the initiation of limb regeneration. Developmental $560 \quad$ Biology, 306(1), 170-178. 
561 Yoshida-Noro, C., \& Tochinai, S. (2010). Stem cell system in asexual and sexual reproduction of

562 Enchytraeus japonensis (Oligochaeta, Annelida). Development, Groth \& Differentiation,

563 52(1), 43-55. https://doi.org/10.1111/j.1440-169X.2009.01149.x

564 Zattara, E. E., Turlington, K. W., \& Bely, A. E. (2016). Long-term time-lapse live imaging reveals

565 extensive cell migration during annelid regeneration. BMC Developmental Biology, 16(6).

566 https://doi.org/10.1186/s12861-016-0104-2.

567 Zheng, P., Shao, Q., Diao, X., Li, Z., \& Han, Q. (2016). Expression of stem cell pluripotency factors

568 during regeneration in the earthworm Eisenia foetida. Gene, 575(1), 58-65.

569 https://doi.org/10.1016/j.gene.2015.08.034.

570 Zrzavý, J., Říha, P., Piálek, L., \& Janouškovec, J. (2009). Phylogeny of Annelida (Lophotrochozoa):

571 Total-evidence analysis of morphology and six genes. BMC Evolutionary Biology, 9(1), 1-14.

$572 \quad$ https://doi.org/10.1186/1471-2148-9-189 
bioRxiv preprint doi: https://doi.org/10.1101/2020.03.01.972448; this version posted March 2. 2020. The copyright holder for this preprint (which was not certified by peer review) is the author/funder, who has granted bioRxiv a license to display the preprint in perpetuity. It is made available under aCC-BY-NC-ND 4.0 International license.

\section{Figures}


wnt8

$\beta$-catenin
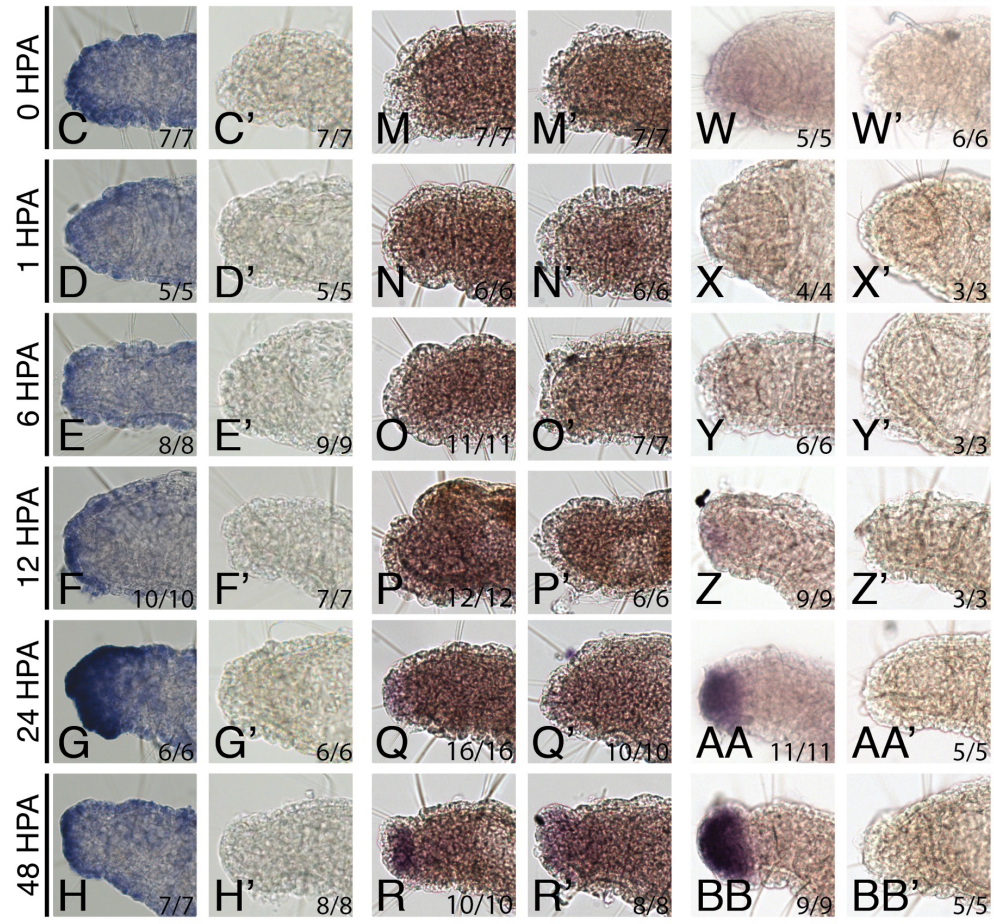

$A^{\prime} A_{11 / 11} A^{\prime} \quad 5 / 5$
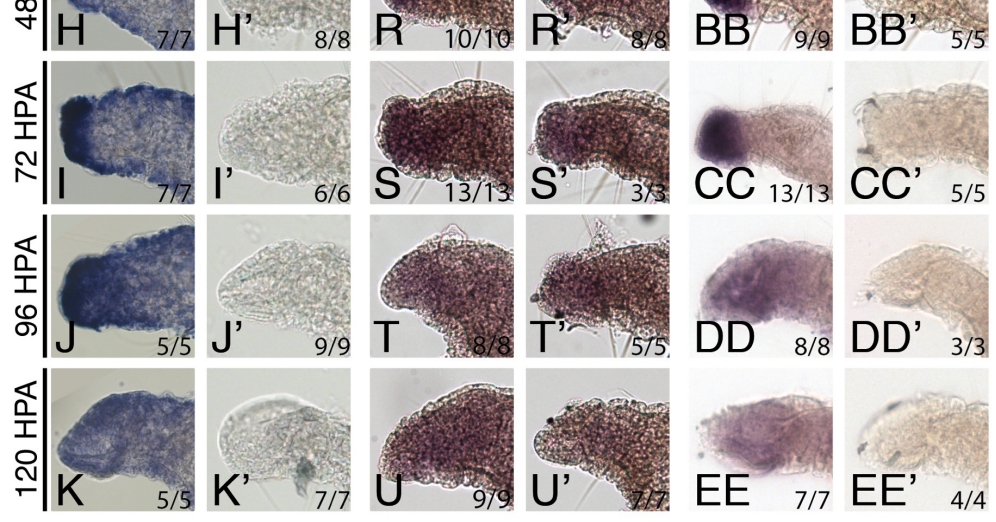
577 Fig. 1. Regenerating wounds show wnt4 and B-catenin activation during blastemal cell

578 proliferation. (A) Dorsal view of an intact worm. Double arrow line indicates posterior

579 synchronizing cutting plane between midgut and hindgut junction. Dotted line indicates the

580 anterior amputation plane between foregut and midgut junction. (C-K') wht4 expression

581 pattern during regeneration. Epithelial wnt4 signal decreased within the first 6 HPA (C-E),

582 followed by activation in the blastema between 24-96 HPA (G-J). (M-U') wnt8 expression in the

583 blastema was indistinguishable from background signals. (W-EE') B-catenin expression pattern

584 during regeneration. 8-catenin was activated in the blastema between 24-72 HPA (AA-CC). In

585 intact worms, wnt4 and B-catenin could be detected at the posterior proliferating segments of

586 intact worms (arrows of $\mathbf{B}$ and $\mathbf{V}$ ). Ratio at the lower right corner indicates specimens showing

587 the corresponding expression patterns. Scale bar in $\mathbf{A}=100 \mu \mathrm{m}$. 




$\mathrm{R}$



品

-

590 Fig. 2. Nuclear $\beta$-catenin suggests Wnt pathway activation during blastemal proliferation at

59124 HPA. (A-D) Ventral view of 24 HPA blastema shows $\beta$-catenin protein (magenta)

592 accumulated in some nuclei (green) as indicated by arrowheads. Some non-specific signals were

593 also detected on the epithelium (arrows). (B-D) Higher magnification of the box region in A. (E-

594 P) Representative images of nuclear $\beta$-catenin at regeneration stages under control or inhibitor

595 treatments. (Q) Intact prostomium of $\beta$-catenin immunohistochemistry stain. (R) The ratio of $\beta$ -

596 catenin $^{+}$nuclei to total blastemal nuclei under different conditions. Control blastema showed

597 highest level of $\beta$-catenin ${ }^{+}$at 24 HPA. Azkp enhanced nuclear $\beta$-catenin level (green line), while

598 XAV down-regulated nuclear $\beta$-catenin level at 24 and 48 HPA (red line). E-Q are maximum

599 projections from ten serial focal planes. Error bars represent the standard deviation of the

600 mean from $>3$ worms. I.P. $=$ Intact prostomium. Scale bar of $\mathbf{C}=100 \mu \mathrm{m} ; \mathbf{C}^{\prime}=10 \mu \mathrm{m}$. Yellow

601 dotted lines of E-P indicate the amputation plane. * denotes $p<0.05$ of $t$-test compared with control at the corresponding time point.

603 
bioRxiv preprint doi: https://doi.org/10.1101/2020.03.01.972448; this version posted March 2, 2020. The copyright holder for this preprint (which was not certified by peer review) is the author/funder, who has granted bioRxiv a license to display the preprint in perpetuity. It is made available under aCC-BY-NC-ND 4.0 International license.

605 Fig. 3. Over-activating and down-regulating Wnt pathway both inhibited regeneration. (A-D)

606 Exogenous Wnt pathway activators (Wnt agonist, Alsterpaullone and Azakenpaullone), and

607 inhibitor (XAV939), inhibited regeneration in dose-dependent manners. (E-M) Lateral view of

608 regeneration stages under control, $0.25 \mu \mathrm{M}$ Azkp or $5 \mu \mathrm{M}$ XAV treatments. Azkp treated worms

609 showed smaller blastema (H-J). XAV939 did not affect blastema formation (K-M), but worms did

610 not regenerate prostomium (compare bracket regions of $\mathbf{G}$ and $\mathbf{M}$ ). (N-O) Successful

611 regeneration rates under $24 \mathrm{H}$ pulses. Regeneration was significantly inhibited by $0.25 \mu \mathrm{M}$ Azkp

612 treatment between 0-24 HPA (N), and by $5 \mu \mathrm{M}$ XAV treatment between 24-48 HPA XAV (0).

613 Anterior end is toward the left and dorsal to the top. Dotted lines indicate cutting planes. Scale

614 bar in $\mathbf{M}=100 \mu \mathrm{m}$. All images are at the same scale. ${ }^{*}$ denotes $p<0.05 .{ }^{* *}$ denotes $p<0.01$. 

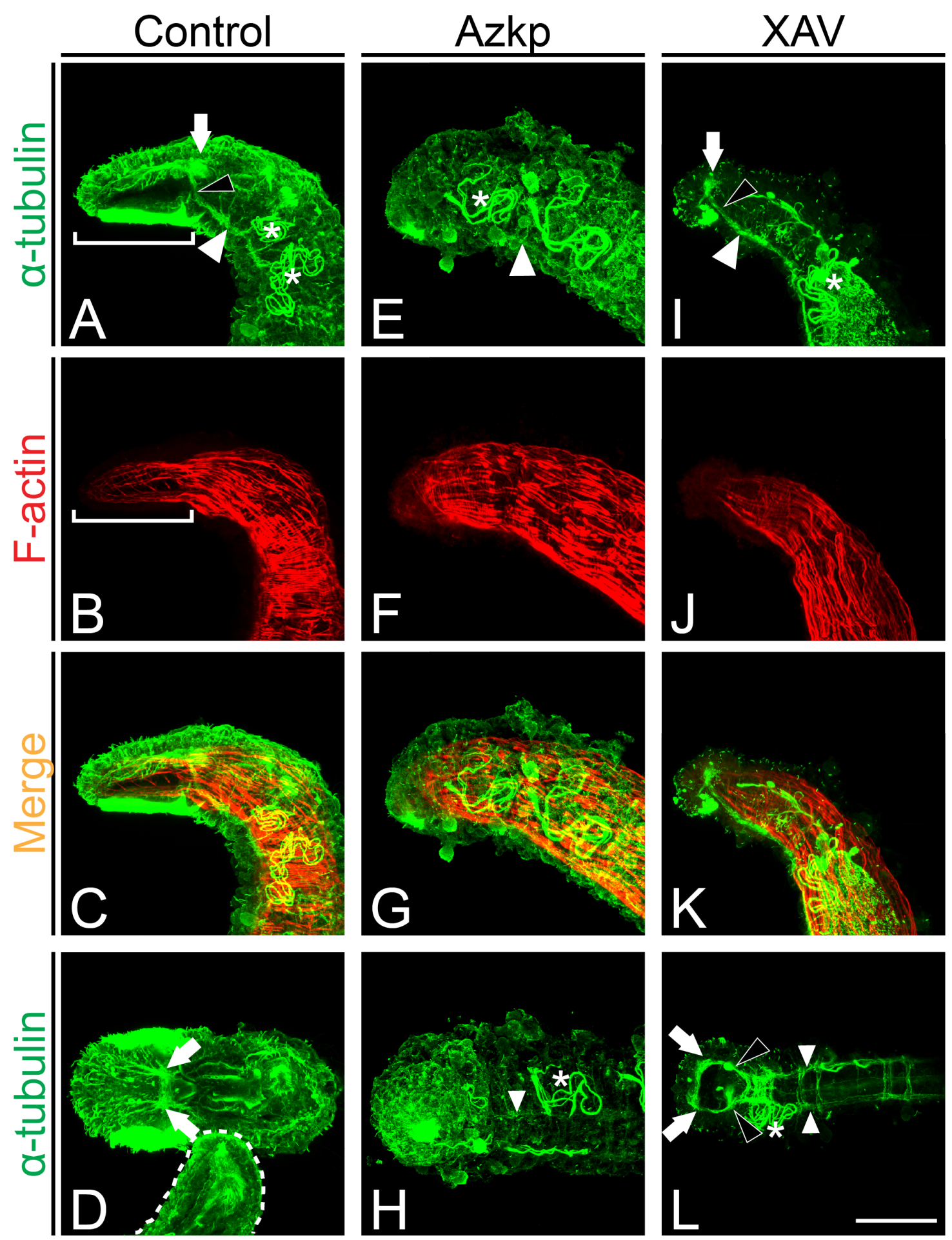

618 By 144 HPA, control worms showed recovered innervation (acetylated $\alpha$-tubulin, green) with

619 neuropil in the prostomium (white arrows) connecting to the ventral nerve cord (white 
620 arrowhead) by the circumesophageal commissures (black arrowhead). The neuropil extended

621 exons dorsal-anteriorly to the epithelial sensory cilia. Ventral prostomial ciliary field was also

622 enriched with acetylated $\alpha$-tubulin (bracket of A). Rhomboid shape-arrayed muscle net (F-actin,

623 red) supported the flat prostomium (bracket region of $\mathbf{B}$ ). The white dotted line in $\mathbf{D}$ delineates

624 the pygidium of the worm. (E-H) Azkp treated worms did not regenerate anterior innervations

625 from the degenerated ventral nerve cord (white arrowheads) and the prostomium (F). (I-L) XAV

626 treated worms regenerated anterior innervation where the neuropil (white arrows) and

627 circumesophageal commissures (black arrowheads) connect to the ventral nerve cords (white

628 arrowheads). However, these worms did not regenerate the prostomium (J). Asterisks indicate

629 metanephridia. Anterior of all amputees are toward the left. Figure A-C, E-G, and I-K are lateral

630 views with dorsal to the top. Figure $\mathbf{D}$ is dorsal view; $\mathbf{H}$ and $\mathbf{L}$ are ventral views. Scale bar in $\mathbf{L}$

$631=100 \mu \mathrm{m}$. All images are at the same scale. 
bioRxiv preprint doi: https://doi.org/10.1101/2020.03.01.972448; this version posted March 2, 2020. The copyright holder for this preprint (which was not certified by peer review) is the author/funder, who has granted bioRxiv a license to display the preprint in perpetuity. It is made available under aCC-BY-NC-ND 4.0 International license.

634 Fig. 5. Over-activating Wnt pathway impaired blastemal cell proliferation. (A-O) Proliferating

635 cells between 24 to 48 HPA are labeled by EdU (magenta) or anti-H3P antibody (yellow). The

636 nuclei are false-colored in cyan. Higher magnification views of white rectangle areas of $\mathbf{A}, \mathbf{F}$ and

$637 \mathrm{~K}$ are in the corresponding lower panels. In control and XAV treated worms, active proliferating

638 blastema showed condensed EdU signals ( $B$ and $\mathbf{L}$ ); while Azkp treatment resulted in less EdU

639 nuclei at the wound site (arrow) and a second domain of proliferating cells in the $2^{\text {nd }}$ segment

640 (arrowhead, G). (J) Single $z$ section image shows that the proliferating cells in the $2^{\text {nd }}$ segment

641 were located at the front end of midgut. Anterior of all amputees are toward the left with

642 dorsal to the top. Black arrowheads in $\mathbf{E}, \mathbf{J}$ and $\mathbf{O}$ delineate the blastema and the segment

643 boundary. (P) Ratio of $\mathrm{EdU}^{+}$nuclei between blastema and the following $2^{\text {nd }}$ segment. Student $t$ -

644 test comparison with control worms shows significant $(p=0.007)$ enrichment of EdU ${ }^{+}$nuclei at

645 the $2^{\text {nd }}$ segment of Azkp treated blastema. Scale bar in $\mathbf{K}=200 \mu \mathrm{m} ; \mathbf{O}=100 \mu \mathrm{m} . \mathbf{A}, \mathbf{F}$ and $\mathbf{K}$ are

646 at the same scale. B-E, G-J and L-O are at the same scale. 
HPA Stage


48


High


\section{muscle contraction}



650 Fig. 6. A proposed model of endogenous Wnt pathway activity during $A$. viride regeneration.

651 A rainbow pallet defines hypothesized blastemal Wnt activities. After amputation, wound

652 closure finishes in the first 6 HPA. Then blastema gradually enlarges at the wound site by cell

653 proliferation. By 72 HPA, blastemal tissue initiates occasional contraction, indicating neuron 
bioRxiv preprint doi: https://doi.org/10.1101/2020.03.01.972448; this version posted March 2, 2020. The copyright holder for this preprint (which was not certified by peer review) is the author/funder, who has granted bioRxiv a license to display the preprint in perpetuity. It is made available under aCC-BY-NC-ND 4.0 International license.

654 and muscle cell differentiation. By 120 HPA, worms complete regeneration with a horseshoe-

655 shaped mouth and can freely glide on substrates.

656 
bioRxiv preprint doi: https://doi.org/10.1101/2020.03.01.972448. this version posted March 2, 2020. The copyright holder for this preprint (which was not certified by peer review) is the author/funder, who has granted bioRxiv a license to display the preprint in perpetuity. It is made available under aCC-BY-NC-ND 4.0 International license.

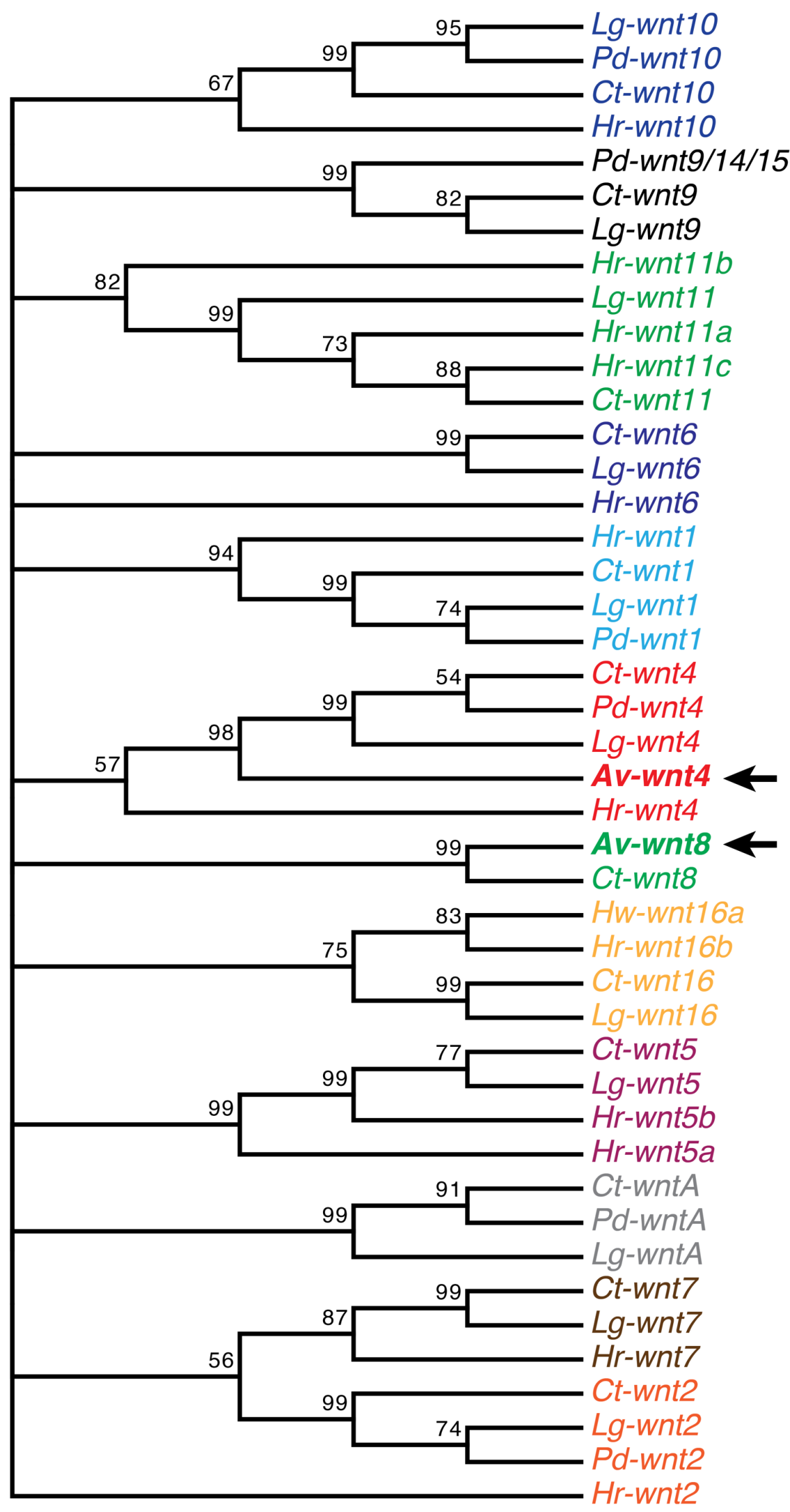


bioRxiv preprint doi: https://doi.org/10.1101/2020.03.01.972448; this version posted March 2, 2020. The copyright holder for this preprint

(which was not certified by peer review) is the author/funder, who has granted bioRxiv a license to display the preprint in perpetuity. It is made available under aCC-BY-NC-ND 4.0 International license.

658 Fig. 7. Neighbor-joining tree clusters $A$. viride wnt genes into the corresponding

659 Lophotrochozoan wnt subfamilies. Av-wnt4 and $A v$-wnt8 are indicated by arrows. Within the

66010,000 replicates bootstrap tests, the percentage of replicate trees in which the associated taxa

661 clustered together are shown at the branches. Note that the nodes with bootstrap percentage

$662<50 \%$ are compressed. Species name abbreviations: Av: Aeolosoma viride; Ct: Capitella teleta;

663 Hr: Helobdella robusta; Lg: Lottia gigantea; Pd: Platynereis dumerilii.

664 



Fig. 8. EdU incubation specifically labeled proliferating cells. The regenerating worms were

667 incubated with or without EdU between 24-48 HPA. Without EdU, background signal appeared

668 only when the contrast of image was highly enhanced ( $\left.\mathbf{B}^{\prime}\right)$. 
Table 1. Degenerate primers initially used to clone Wnt pathway related genes.

\begin{tabular}{|l|l|}
\hline Primer name & Sequence \\
\hline wnt4-F1 & CCDCGYGGRCAGCAAAGCA \\
\hline wnt4-R1 & ARTGCAARTGTCATGGHGTG \\
\hline 6-catenin-F1 & GTGCGHCTGGCYGGHGGRYTCA \\
\hline b-catenin-R1 & CRGCYRTVTGTGCTCTTCGTC \\
\hline
\end{tabular}

672 Code: $M=A$ or $C ; B=C, G$, or $T ; R=A$ or $G ; Y=C$ or $T ; V=A, C$, or $G ; H=A, C$, or $T$.

674 Table 2. Primers for 5' and 3' RACE. Note that wht4-R2 and 6-catenin-R2 were used as gene 675 specific primers for first strand CDNA synthesis during reverse transcription of 5' RACE.

\begin{tabular}{|c|c|c|c|}
\hline Primer name & Sequence & Primer partner & Amplification target \\
\hline $3^{\prime} \mathrm{AP}$ & $\begin{array}{l}\text { GGCCACGCGTCGACTAGTACTTTTTTT } \\
\text { TTTTTTTTTTTTT }\end{array}$ & & \\
\hline 3' AP head & GGCCACGCGTCGACTAGTAC & & \\
\hline $5^{\prime} \mathrm{AP}$ & $\begin{array}{l}\text { GGCCACGCGTCGACTAGTACGGGG } \\
\text { GGGGGGGGGGGG }\end{array}$ & & \\
\hline 5' AP head & GGCCACGCGTCGACTAGTAC & & \\
\hline wnt4-F2 & TTCAAAGCGTTGGCACAAGACTGC & 3' AP & wnt4 cDNA and wnt4 $3^{\prime}$ RACE $1^{\text {st }}$ nested PCR \\
\hline wnt4-F3 & TCAAGGCACACGTGACGTTCTACA & 3' AP head & wnt4 3' RACE $2^{\text {nd }}$ nested PCR \\
\hline wnt4-R2 & GGTGAAGGCACTAGGTACACTAG & $5^{\prime} \mathrm{AP}$ & wnt4 5' RACE $1^{\text {st }}$ nested PCR \\
\hline wnt4-R3 & TGTAGAACGTCACGT & 5' AP head & wnt4 5' RACE $2^{\text {nd }}$ nested PCR \\
\hline wnt8-F1 & GTGGACGAACACTGCGGCTGCA & $3^{\prime} \mathrm{AP}$ & wnt8 $3^{\prime}$ RACE $1^{\text {st }}$ nested PCR \\
\hline wnt8-F2 & GCGTTGCTCTCAGCCAACCGAA & 3' AP head & wnt8 3' RACE $2^{\text {nd }}$ nested PCR \\
\hline 8-catenin- $\mathrm{F} 2$ & GATGCTGCTACTAAAGTGGATG & 3' AP & b-catenin $3^{\prime}$ RACE $1^{\text {st }}$ nested PCR \\
\hline 8-catenin-F3 & GCAAGAGGGTGCCACAGCTCC & $3^{\prime} \mathrm{AP}$ & 8-catenin 3' RACE $2^{\text {nd }}$ nested PCR \\
\hline 8-catenin-F4 & GACACCGTGGTACGACACGG & 3' AP & 6-catenin 3' RACE $3^{\text {rd }}$ nested PCR \\
\hline 8-catenin-R2 & GCCACCAGCTTCAACAACAGCAGG & & 8-catenin cDNA \\
\hline 8-catenin-R3 & GTTCACCAGGACCTCCAGAAGCC & $5^{\prime} \mathrm{AP}$ & b-catenin 5' RACE $1^{\text {st }}$ nested PCR \\
\hline 8-catenin-R4 & TAGCTTGCTTTCTTGGTTACC & 5' AP head & 8-catenin 5' RACE $2^{\text {nd }}$ nested PCR \\
\hline
\end{tabular}

Table 3. Primers for synthesizing riboprobe templates.

\begin{tabular}{|c|c|c|}
\hline Primer name & Sequence & Target product length (bp) \\
\hline wnt4_ISH-F1 & CATGTTGGAGAGCGCTGCC & \multirow{2}{*}{792} \\
\hline wht4_ISH-R1 & CATGTGTATTCGTTGATGTGCAC & \\
\hline wnt8_ISH-F1 & CGGAGAGATGGTGAGTCGCCTT & \multirow{2}{*}{934} \\
\hline wht8_ISH-R1 & TGTGCGGGCGTGCTTTGCGTAT & \\
\hline b-catenin ISH-F1 & CGCAATGAAGGAGTTGCCAC & \multirow{2}{*}{885} \\
\hline 6-catenin_ISH-R1 & TCGTCTACCATGTACACAGG & \\
\hline
\end{tabular}

